\title{
Kinetics of photorestoration of copper(II) in compositions on the basis of acetate of copper and the tetraftorpropianat of copper
}

\author{
(C) Ludmila A. Brusnitsina, ${ }^{{ }^{+}}$Elena I. Stepanovskih, and Tatiana A. Alexeeva \\ Physical Chemistry and Chemistry of Colloids Academic Department. \\ Ural Federal University Named after the First President of Russia B.N. Yeltsin. \\ Mira St., 19. Yekaterinburg, 620002. Russia.E-mail: brusnitsyna.l@yandex.ru
} \begin{abstract}
Keywords: copper photo recovery, kinetic patterns, surface activation, dielectric materials.
\end{abstract}
*Supervising author; ${ }^{+}$Corresponding author

\begin{abstract}
In the technology of manufacturing printed circuit boards by additive method, photoselective activation of dielectric materials is widely used. In order to obtain a given circuit pattern on the surface and in the holes of the printed circuit board it is necessary to form catalytically active centers for further chemical metallization.

The aim of the work was to study the physical and chemical patterns of the photoactivation process of dielectric materials. Copper acetate $\left(\mathrm{CuAc}_{2}\right)$ and copper tetrafluoropropyanate $\left(\mathrm{Cu}(\mathrm{TFP})_{2}\right)$ having sufficiently high spectral sensitivity to UV radiation and good solubility in water were added to the analysed photosensitive compositions as copper-containing compounds (photopromotors).

Chemical sensitizer in analysed photosensitive compositions is water-soluble organic compound - disodium salt of anthraquinone-2,6-disulfonic acid $\left(\mathrm{Na}_{2} \mathrm{AS}\right)$, acting as optical sensitizer in processes of photochemical reduction of copper(II). The process of photochemical reduction of copper(II) in the presence of sensitizers is possible with the presence of secondary reducing agents - alcohols. Such compounds are sorbitol and ethyl alcohol.

In comparison with solutions, the study of the process of photo recovery of copper(II) in the dry layer of the photoactivator under the influence of ultraviolet radiation requires a special approach. A quantitative evaluation of the photochemical process was chosen to pass the photosensitive layer. On the transmission spectra of the photosensitive layer, it is clearly possible to distinguish a maximum at a wavelength of $520 \mathrm{~nm}$, from the change of which during ultraviolet irradiation it is possible to judge the progress of photochemical transformation in the dry layer of photocomposition. The kinetics of the photochemical process were monitored by the transmission spectra of the $520 \mathrm{~nm}$ samples, which were taken immediately after irradiation. Survey of spectra was carried out on spectrophotometer of grade CF-18 in visible region of spectrum relative to chromatographic paper FN-5 without photoactivator.

Mercury-quartz lamp of DRT-1000 grade was used as radiation source. Exhibiting carried out on GG-2258 installation in a special vacuum frame at distance $40 \mathrm{~cm}$ from a radiation source

A phenomenological description is given of the process of photo-recovery of copper(II) in solid phase in compositions based on copper acetate and copper tetrafluoropropionate in form of kinetic equations. Fractional partial reaction orders by components of the photocomposition indicate the complexity of the process in the systems studied.

It has been found that, depending on the kind of copper-containing compound, the process of copper photorecovery is described by different kinetic equations, suggesting a different mechanism of copper(II) photorecovery. It has been shown that complicating the composition of the photosensitive composition results in a slight change in the reaction order of the main components.

The description of the kinetics of the photochemical process by means of mathematical equations will allow to determine in advance the time by which the specified degree of conversion of the substance will be achieved.
\end{abstract}

\section{References}

[1] W. Backenbaugh, D. Dinella, T.A. Polakowski. Metal Finishing. 1982. Vol.4. P.11-16.

[2] W. Backenbaugh, D. Dinella, T.A. Polakowski. Metal Finishing. 1982. Vol.5. P.39-43.

[3] L.A. Brusnitsina, E.I. Stepanovskih, T.A. Alekseeva, A.O. Osipchuk, and B.V. Budanov_Quantum-chemical modeling of photoreduction of copper acetate. Butlerov Communications. 2016. Vol.46. No.5. P.95-103. https://doi.org/10.37952/ROI-jbc-02/16-46-5-95

[4] P.V. Myklyar. Physical processes in the formation of a hidden photographic image. Moscow: Science. 1972. 399p. (russian)

Kazan. The Republic of Tatarstan. Russia. (C)Butlerov Communications. 2020. Vol.62. No.4. 
[5] B. Renbi, Ya. Rabek. Photodestructive, photooxidation, photostabilization polymers. Moscow: Chemistry. 1978. 675p. (russian)

[6] G.M. Panchenkov, V.P. Lebedev. Chemical kinetics and catalysis. Moscow: Chemistry. 1985. 360p. (russian)

[7] L.A. Brusnitsina, E.I. Stepanovskih, T.A. Alekseeva, and V.I. Dvoinin. Photoreduction process modeling of copper(II) in the solid phase. Butlerov Communications. 2012. Vol.29. No.1. P.75-79. ROI-jbc-02/12-29-1-75

[8] L.A. Brusnitsina, T.A. Alekseeva, and E.I. Stepanovskih. Optimization of the photocomposition for dielectric activation before chemical metallization. Butlerov Communications. 2018. Vol.53. No.3. P.75-81. https://doi.org/10.37952/ROI-jbc-02/18-53-3-75

[9] M. Brown, D. Dollimor, Galvit And. Reactions of solid bodies. Moscow: World. 1983. 360p. (russian) 